\title{
Butterfly e a dramaturgia do movimento: da figura à transfiguração do corpo - construindo Kate Sherman ${ }^{1}$
}

\author{
Prof. Dr. Milton de Andrade Leal $\mathrm{Jr}^{2}$ Barbara Biscaro ${ }^{3}$ \\ Participantes da pesquisa: Juarez José do Nacimento ${ }^{4}$, Barbara \\ Biscaro $^{5}$, Samuel Romão ${ }^{6}$, Monica Siedler ${ }^{7}$
}

Palavras-chave: corpo - dramaturgia - grotesco - personagem - dança

Resumo: O presente artigo é resultado de uma pesquisa teórico-prática que discute as relações entre os procedimentos técnicos do treinamento do ator e a construção de novas abordagens dramatúrgicas nas artes cênicas. A noção de um espaço dramatúrgico que deve ser edificado revelase como um terreno fértil para o jogo e para a criação do movimento e define a busca de significação e construções simbólicas em sala de trabalho e sua aderência no campo da pesquisa teórica e dramatúrgica. A partir da contextualização temática, passa-se a tratar do processo de composição da personagem Kate Sherman para o espetáculo "Butterfly", resultado prático desta pesquisa, descrevendo procedimentos utilizados e relacionando-os com termos como o grotesco. A artista plástica norte-americana Cindy Sherman é citada, como uma das principais bases de inspiração e apropriação de procedimentos para a composição da personagem. Deste modo, compreende-se como o processo prático de construção do ator dialoga com pesquisas teóricas, criando um espaço de reflexão e compreensão dos materiais abordados no processo da pesquisa e da composição de uma dramaturgia pautada no movimento corporal.

A montagem de Butterfly 8 foi o universo estabelecido para o desenvolvimento de pesquisas teórico-práticas acerca da formação técnica do ator-dançarino, da composição corporal através do movimento e as possibilidades de recriação cênica e sistematização de uma dramaturgia baseada no corpo do intérprete.

\footnotetext{
${ }^{1}$ Projeto de Pesquisa: Ritos da metamorfose corporal: entre a dança, a dramaturgia do corpo e a psicofísica do ator

${ }^{2}$ Orientador - Departamento de Artes Cênicas/ Centro de Artes - Av. Madre Benvenutta, 1907, Itacorubi - Florianópolis $-\mathrm{SC}$.

3 Bolsista de Iniciação Científica do Curso de Artes Cênicas - CEART-UDESC.

${ }^{4}$ Acadêmico Curso de Educação Artística - Habilitação em Artes Cênicas, CEART/UDESC, bolsista de iniciação científica do PROBIC/ UDESC.

${ }^{5}$ Acadêmica Curso de Educação Artística - Habilitação em Artes Cênicas, CEART/UDESC, bolsista de iniciação científica do PROBIC/ UDESC.

${ }^{6}$ Participante da Pesquisa e Acadêmico Curso de Educação Artística - Habilitação em Artes Cênicas, CEART/UDESC.

${ }^{7}$ Participante da Pesquisa Acadêmica do Programa de Pós-graduação em Teatro, CEART/UDESC.

${ }^{8}$ A estréia e a temporada do espetáculo Butterfly aconteceram na sala Lindolf Bell, de 28 de outubro a 05 de novembro de 2006, no Centro Integrado de Cultura (CIC) em Florianópolis (SC).
} 
Primeiramente foram estudadas as referências literárias, como a obra original Madame Butterfly (1898) do escritor americano John Luther Long (1861-1927) e sua posterior versão lírica Madama Butterfly (1904) do compositor italiano Giacomo Puccini (1858-1924), como bases para a elaboração de um pré-roteiro e de possíveis funções dramáticas a serem exploradas. Porém, o estudo acerca dos mitos envolvidos nos elementos aparentes deste imaginário proposto, como a borboleta e suas significações simbólicas e culturais em diversos lugares do mundo, seus ciclos de transmutações em larva, crisálida e "ser que voa", serviram de aporte para a ampliação das chaves de leitura das referências iniciais e de combustível para a composição de padrões de movimentos, matrizes e criações individuais de cada ator-dançarino.

A transformação cíclica da borboleta engloba uma metáfora na qual o corpo do atordançarino sofre sucessivas transformações até constituir-se elemento estético, pleno de interioridade e um foco de significação expressiva, fruto de seu trabalho e de seu contexto. Pois o corpo não apenas relaciona-se com o ambiente, mas ele próprio é um ambiente que se funde ao entorno.

Já há alguns anos o "onde" deixou de ser apenas o lugar em que o artista se apresenta,
transformando-se em um parceiro ativo dos produtos cênicos. Ao invés de lugar, o onde
tornou-se uma espécie de ambiente contextual. (...) Mas o que importa ressaltar é a
implicação do corpo no ambiente, que cancela a possibilidade de entendimento do mundo
como um objeto aguardando um observador. Capturadas pelo nosso processo perceptivo, que
as reconstrói com as perdas habituais a qualquer processo de transmissão, tais informações
passam a fazer parte do corpo de uma maneira bastante singular: são transformados em corpo.
(GREINER e KATZ, 2005: 130)

Esta noção de espaço corporal fundido ao espaço externo que envolve o corpo é um conceito amplamente exercitado dentro da técnica da dança moderna. Neste aspecto técnico acerca do treinamento do corpo é possível encontrar as bases para o ator-dançarino compreender que a relação do corpo com o espaço é de fusão e reciprocidade. O corpo que dança luta com o próprio peso, sucumbindo ou vencendo-o, inserido em um esquema rítmico e eucinético, de transporte de apoios, de variação de densidades, de consciência da direcionalidade do movimento. O espaço corporal usa o espaço em torno como o meio onde é possível prolongar os limites do corpo, onde é necessário agir e sofrer ações, mutuamente.

E desse mesmo modo, pleno de reciprocidades, é que o contentor dramatúrgico propõe a delimitação de diversos espaços onde o corpo vai inserir-se e agir, de modo a criar significados, proliferar imagens. São funções dramáticas adotadas por cada ator-dançarino, são objetos que se constituem como uma condensação do espaço, são relações desenvolvidas entre corpos que se movimentam, é o universo sonoro selecionado que se constitui como espaço audível e espaço dramático a ser composto pela dramaturgia do movimento.

Vassily Kandinsky (1866-1944), artista plástico russo que desenvolveu seu trabalho com 
pintura abstrata na Europa, no início do século XX, desenvolve uma teoria sobre as “correspondências" entre as artes e os efeitos cinestésicos por elas causados, "chegando ao ponto de tentar estabelecer uma série de equivalências entre sons, cores e movimento, os três elementos que, em sua terminologia, compunham a "obra de arte monumental" (SANCHEZ, 1999: 16, trad. Nossa). Kandinsky afirma que a composição cênica possui três elementos: o movimento musical, o movimento pictórico e a dança.

\begin{abstract}
Do mesmo modo que os dois elementos principais da pintura (as formas gráfica e pictórica) têm uma vida independente e falam através de meios próprios e exclusivos, e do mesmo modo que a composição pictórica surge da combinação destes elementos e de todas as qualidades e possibilidades, assim surge a composição na cena com a colaboração dos três movimentos citados. (KANDINSKY, 1972: 106-108, trad. nossa)
\end{abstract}

Deste modo, Kandinsky revela mecanismos de composição da pintura abstrata que possuem equivalências nos modos de composição de outras artes, frisando que o domínio dos instrumentos de criação e a noção de combinação entre as diversas partes desenvolvidas possibilitam ao artista o desenvolvimento de sua capacidade de composição.

Este tipo de teoria ajuda a compreender os princípios de criação da dramaturgia do movimento, ou uma dramaturgia pautada no corpo do intérprete. O domínio de uma técnica corporal, aliado a um espaço dramatúrgico delimitado e amplamente pesquisado, a utilização de objetos, volumes, peças de vestuário nos processos de criação, a definição coerente de um universo sonoro que se relaciona com a temática proposta são alguns dos elementos motores da criação de materiais a serem organizados e compostos a fim de darem origem a essa dramaturgia pautada no movimento, seja ele corporal, sonoro ou visual.

Compreendendo então estes princípios é possível aprofundar a reflexão acerca do trabalho de criação do ator-dançarino, inserido neste contexto de composição e estruturação de uma dramaturgia do movimento.

A partir deste princípio de construção dramatúrgica e desse universo específico abordado pela pesquisa, uma das funções femininas a serem desenvolvidas foi a figura de Kate, a esposa americana do marinheiro Pinkerton, homem que ilude e conduz ao destino trágico a gueixa Cio-Cio San no libretto da ópera Madama Butterfly (1904) de Giaccomo Puccini.

A personificação desta "mulher americana" e suas relações com as outras funções dramáticas selecionadas na dramaturgia estabeleceu-se como o ponto de partida para o trabalho da atriz-dançarina. A pesquisa prática realizada, então, com objetos, roupas, acessórios cotidianos e abstratos foi baseada no princípio de transfiguração do corpo feminino. Ao reproduzir os antigos moldes dos jogos de "recorte e cole", deu-se vida a uma teatralidade implícita na ambigüidade da figura construída. A beleza convive com a monstruosidade provocando o estranhamento do olhar, 
evocando um universo divertido permeado pela incerteza: será que é isso mesmo que meus olhos vêem? Esta incerteza permanente no olhar do espectador impulsiona a multiplicação dos significados emitidos pela figura, que é desconstruída repetidamente, esfacelando qualquer desejo de rótulos ou impressões estáticas.

Esta multiplicação de significados dentro da figura construída se remete ao conceito de grotesco, mecanismo abordado e utilizado de diversas formas na história do teatro ocidental. Tem suas origens como reflexão estética no Prefácio de Cromwell (1827), texto de Vitor Hugo (18021885), no qual ele aponta o grotesco como o lado dionísiaco a ser explorado no teatro, que irá estabelecer contraponto com a estética apolínea e permitir refundar a teatralidade de sua época. Porém, cumpre ressaltar que a Commedia dell'arte e o Teatro Medieval utilizaram amplamente os mecanismos do grotesco para desenvolver suas potencialidades, herança esta que será recuperada por pesquisadores e renovadores da linguagem teatral novecentista como Vsevolod Meierhold (1874-1940).

O mecanismo de construção da figura do ator em prol da desconstrução e ampliação dos significados presentes em uma dramaturgia teatral se remete às pesquisas do encenador russo Meierhold, que desenvolveu suas pesquisas teatrais no início do século vinte. O grotesco, mecanismo presente nos métodos de sua pesquisa teatral junto aos atores, elucida procedimentos que transformaram o conceito de dramaturgia teatral, ajudando a devolver a teatralidade para a composição cênica, eliminando o culto ao texto dramático e ao poeta como os elementos mais importantes do teatro. A definição do grotesco para Meierhold é:

(...) a exageração e transformação intencional (alteração) de dados naturais. Além de associar objetos que a própria natureza ou a nossa experiência cotidiana habitualmente não conciliam, coloca em relevo as características de uma acentuada deformação. (BONFITTO, 2002: 42)

Meierhold utiliza o grotesco para definir a própria teatralidade. Ele não considerava o grotesco um estilo, mas um método. A busca pela descoberta de novas significações a partir das relações entre a ação física e os objetos está presente em toda obra de Meierhold. E este procedimento relaciona-se diretamente com os processos de composição do espetáculo teatral, onde o universo dramatúrgico estabelecido pelo texto dramático será expandido, recriado, colocado em contradição e re-proposto. Isto se dá a partir do próprio corpo do ator e o modo como este corpo se relaciona com objetos, com a deformação do corpo através do vestuário e próteses e com a relação entre corpo e espaço cênico, ampliando a gama de signos teatrais a serem desvendados pela pesquisa dramatúrgica e seu processo de composição.

Meierhold parece reconhecer no grotesco, a possibilidade de dar uma unidade às suas pesquisas, de ser um denominador comum resultante a observação e do estudo de diferentes formas teatrais. $\mathrm{O}$ grotesco enquanto revelador de estruturas profundas da realidade a partir da utilização de contrastes: cômico e trágico. Mas o grotesco também enquanto definição de 
um tipo de ator, um ator sintético. (BONFITTO, 2002: 42-43)

Deste modo, a transformação do corpo do ator é uma busca incessante de novos estados corporais, da ampliação de limitações naturais impostas pelo corpo e seu aspecto anatômico; porém somente o exercício estilístico de transmutações sucessivas pode renovar a teatralidade da construção corporal. O movimento ou o não-movimento gerado pela experimentação prática deve estabelecer paralelos com os elementos delimitados em um universo dramático, uma gama de significações e seus correspondentes culturais, suas referências em outras formas artísticas e seus equivalentes no mundo cotidiano. Deste modo, a construção plástica ganha interioridade, emana significados múltiplos a serem organizados em cena e exibe uma função eficaz na edificação da dramaturgia composta a partir do corpo do ator.

Este perpétuo movimento de inversão das perspectivas provoca a contradição entre o objeto realmente visto e o objeto imaginado: visão concreta e abstração intelectual caminham sempre juntas." (PAVIS, 1999: 189)

No processo de composição das figuras femininas ligadas ao imaginário da "mulher americana", na pesquisa acerca do universo de "Butterfly", uma das aproximações realizadas com outras linguagens artísticas como referência para a construção corporal foi a obra da artista plástica americana Cindy Sherman (1954 - ). ${ }^{9} \mathrm{Na}$ série fotográfica Untitled Film Stills, (do período de 19771980), Sherman realiza um trabalho em que fotografa si mesma em várias situações, encarnando diferentes figuras femininas. Estas figuras, construídas com esmero através de roupas e maquiagem, se remetem a estereótipos femininos, divas do cinema, mulheres em situações cotidianas, compondo um retrato multiforme da identidade feminina onde por trás de cada imagem há somente uma pessoa: a própria artista. Este jogo denuncia que o olhar do outro pode ser a origem da construção da identidade, fazendo da imagem um suporte para a projeção dos desejos de quem a observa. E este fluxo entre a imagem construída e as projeções implícitas em sua aparência é o ponto de partida para compreender quem pode ser esta "mulher americana", que corpo evoca e que relações pode produzir na relação com os outros elementos do universo dramatúrgico.

Aquelas pequenas fotografias em preto-e-branco de Sherman personificando várias personagens femininas dos filmes B e filmes noir falou para um geração de mulheres que havia crescido absorvendo aquelas imagens glamourosas em casa, nas suas televisões, tomando tais retratos como pistas para seus futuros. Com cada série subseqüente de fotografias, Sherman imitou e confrontou variadas alegorias representacionais, explorando os milhares de modos onde as mulheres e o corpo são retratados por eficazes produtores de imagens contemporâneos, incluindo a mídia de massa e fontes históricas como contos de fadas, a arte dos retratos e a fotografia surrealista. (CRUZ, 1997: 1, trad. nossa)

Cindy Sherman relata no texto The Making of Untitled (2003) escrito para o catálogo The Complete Untitled Film Stills (2003) que um dos procedimentos para a composição de seu trabalho foi dirigir- 
se para locais públicos ou para o escritório onde trabalhava vestida com as figuras que criava, envergando aquela imagem diversa da dela dentro do seu cotidiano, destacando-se como uma figura colorida em um mundo preto-e-branco. Deste modo, sem tentar interpretar a figura teatralmente, ela testava a eficácia de sua composição e podia compreender como uma mulher se moveria ou precisaria se comportar se envergasse aquelas roupas ou aquela aparência e como seria a reação daqueles que a observam. Este procedimento foi transposto para a presente pesquisa do seguinte modo: a atriz, ao invés de ir trabalhar com roupas adequadas para a realização dos movimentos exigidos pelo treinamento físico e pela dança, ia aos ensaios envergando uma figura composta, não importando se as roupas ou acessórios limitassem os movimentos. Mas esta figura feminina composta não poderia ser "normal": precisava apresentar elementos como exageração de partes do corpo, amarras em articulações, prolongamento dos membros, omissão de partes do corpo. Deste modo, o corpo que comparecia ao trabalho exibia uma série de limitações, porém exigia que fossem encontrados outros mecanismos motores para fazer com que cada figura dançasse, ao seu modo. Assim, figuras eram selecionadas e descartadas, dando material para as pesquisas dentro do universo proposto.

A figura feminina construída reproduz o afeto evocado pelo olhar externo, jogando com os planos do vazio e do cheio: a significação é dada pelo olhar exterior que termina de compor a figura projetando nela as suas próprias referências pessoais. Se é possível reconhecer uma aeromoça ou uma enfermeira é porque aquele olhar propõe esta leitura, porém o processo de composição não é permeado pela escolha desse tipo de temática para ser desenvolvido. Como uma boneca que ganha vida através da menina, como um anúncio publicitário que ganha valor através da identificação ou do desejo de se tornar algo que mora na imagem, o jogo de formação da figura está na elaboração de combinatórias que possuam um molde plástico que vai terminar de ganhar valor no confronto com o outro. Uma colagem de referências culturais e da construção do mito feminino através das imagens geradas pelo cinema, pela pintura, pela moda, pela publicidade e outros meios de veiculação altamente difusores de imagens dos modelos femininos. Estes princípios estão também na base do trabalho fotográfico de Sherman:

Já que as personagens de Sherman em Untiltled Film Stills não são especificadas, nós ficamos livres para construir nossas próprias narrativas para essas mulheres. Sherman encoraja nossa participação, ao sugerir, através da natureza deliberada de suas poses, que ela é o objeto da contemplação de alguém. (CRUZ, 1997: 3, trad. nossa)

\footnotetext{
${ }^{9}$ Tal pesquisa foi proposta e aprofundada por Monica Siedler, participante de nosso projeto de pesquisa, através da elaboração de sua dissertação a ser apresentada no âmbito do Programa de Pós-Graduação em Teatro (PPGT) da UDESC.
} 
Porém, a empatia gerada por esta figura com elementos estranhos à forma natural do corpo é essencial para disparar um mecanismo de reconhecimento e repulsa, através do qual se compreende até que ponto se é atraído ou repelido pela compreensão do corpo feminino construído que dança. A empatia com a figura, o deslumbramento é necessário para o estabelecimento de vínculo e a eficácia do elemento estranho/bizarro que vai manchar a figura, estilhaçar o olhar do espectador e inverter a ordem do mundo na busca pela teatralidade. A beleza evita a compaixão, o elemento estranho evita a plastificação da figura, deixando os procedimentos em consonância com as idéais de Meierhold sobre o grotesco:

O que é essencial no grotesco é o modo constante com o qual ele desloca o espectador de um plano perceptivo que acabou de intuir, para um outro que ele não esperava. (BONFITTO, 2002: 43)

Todas as pessoas possuem um grau de construção de si mesmas a partir de colagens de referências do mundo exterior que reverberam ante os desejos do mundo interior. $\mathrm{O}$ desejo provoca a construção de uma imagem que satisfaça o olhar individual e o olhar externo: aquilo que pareço diante do mundo dá pistas claras sobre aquilo que desejo ser ou que desejo ser tomado como. Assim, pode-se dizer que as informações que circulam dentro e fora do corpo, ao se tornarem concretamente reais, ao agirem no espaço e no tempo presentes, não são meros dispositivos estéreis à espera de significação somente a partir do outro: elas se transformam em corpo e habitam a ação, indissociáveis de seu ambiente e plenas de significação em diversas camadas semânticas.

O corpo não é um lugar onde as informações que vêm do mundo são processadas para serem depois devolvidas ao mundo.

O corpo não é um meio por onde a informação simplesmente passa, pois toda informação que chega entra em negociação com as que já estão. O corpo é o resultado desses cruzamentos, e não um lugar onde as informações são apenas abrigadas. (GREINER e KATZ, 2005: 130131)

Neste sentido, a construção das figuras femininas colocadas dentro da dança revela um jogo natural do ser humano de querer ser: mas este corpo preparado é colocado em movimento e a partir de suas contenções e possibilidades gera um tipo de movimentação que compõem o universo em que a figura emerge. A partir então do jogo corporal e da relação com o outro, que projeta e recebe os desejos sobre o corpo construído, a figura ganha autonomia de signos e compõe um universo paralelo dentro de um outro ponto de ambigüidade: densa, e ao mesmo tempo superficial, a figura feminina construída constitui-se como informação e abre o olhar do espectador, corroborando ou destruindo as referências pessoais, possibilitando alargar as chaves de leitura acerca de um préconceito sobre a identidade desta "mulher americana" re-proposta pelo trabalho da atriz dentro do contentor dramatúrgico estabelecido.

Retomando as reflexões acerca da composição de uma dramaturgia do corpo, podemos 
concluir que é necessário estipular parâmetros concisos dentro das pesquisas teatrais e em dança que aprofundaram estas relações estéticas e técnicas e fizeram emergir uma nova teatralidade dentro do corpo que dança e a possibilidade cada vez mais explorada de compor novas dramaturgias, renovando as pesquisas estéticas nas artes cênicas.

O uso de recursos de encenação, antes pertencentes a outros universos artísticos, são transpostos para as obras de dança, e isso resulta na sua fusão com a teatralidade e a indefinição dos gêneros antes distintos. Esses recursos apóiam a estruturação de novas dramaturgias, agora pautadas no movimento.

Disso resulta a criação de uma fábula e de uma dramaturgia que contam uma história a partir das ações simbólicas das personagens - que permanecem no seu papel e são condutoras da dramaturgia. ( PAVIS, 1999; p. 84)

O corpo do ator-dançarino, então, torna-se o terreno onde se fundará estas experiências de fusão das linguagens, aproximando o movimento abstrato de ações miméticas, aproximando a construção de figuras ou personagens com sua capacidade cinética, aproximando a técnica da dança com a criação de estados corporais e núcleos de significações simbólicas dentro de um contexto de criação dramatúrgica.

\footnotetext{
Ao valer-se contemporaneamente dos ingredientes de uma encenação teatral, como inserção de textos, cenografia, objetos-figurinos, a dança-teatro acaba investindo na criação de uma dramaturgia que conta uma história: as ações simbólicas das personagens são ligadas em algum grau, ainda que de maneira abstrata, a motivações psicológicas ou sociológicas. ( NASPOLINI, 2006; p. 59)
}

Deste modo, a composição da dramaturgia do movimento, aliada à busca de novas respostas corporais por parte dos intérpretes diante do desafio de estruturar uma obra cênica, corresponde ao trabalho incansável de edificar núcleos poéticos a serem desenvolvidos em pesquisas na área do teatro e da dança, provocando sucessivos rompimentos com as fronteiras que separam este teatro poético e cinético de linguagens como a música e as artes plásticas, retornando ao espectador com resultados genuínos de investigação artística.

\section{REFERÊNCIAS}

BONFITTO, Matteo. O ator compositor. São Paulo: Perspectiva, 2002.

CRUZ, Amada. Movies, Monstrosities, and Masks: twenty years of Cindy Sherman. In. Cindy Shermana: Retrospective. New York: Thames \& Hudson, 1997.

GREINER, Christine e KATZ, Helena. Por uma teoria do corpomídia. In. O Corpo - pistas para estudos indisciplinares. São Paulo: Anna Blume, 2005 
KANDINSKY, Vassily. De lo espiritual en la arte. Barcelona: Barral Labor, 1972.

NASPOLINI, Marisa. Corpos em Ação: a construção da personagem na dança. In. Tubo de Ensaio - Experiências de Dança e Arte Contemporânea. Florianópolis: Ed. Do Autor, 2006.

PAVIS, Patrice. Dicionário de Teatro. São Paulo: Perspectiva, 1999.

SANCHEZ, José (ed). La Scena Moderna- manifiestos y textos sobre teatro de la época de vanguardias. Madri: Ediciones Akal, 1999.

SERVOS, Norbert. Entre a Alegria e a perfídia. In. Revista Bravo n. 39. São Paulo: Editora D 'Ávila, 2000.

SHERMAN, Cindy. The Making of Untitled. In: The Complete Untitled Film Stills. New York: The Museum of Modern Art, 2003. 